Revista Eletrônica de Ciência Administrativa (RECADM) - ISSN 1677-7387

Faculdade Cenecista de Campo Largo - Coordenação do Curso de Administração

v. 4, n. 1, maio/2005 - http://revistas.facecla.com.br/index.php/recadm/

\title{
ASPECTOS RELEVANTES DA APROXIMAÇÃO ENTRE BRASIL E CHINA: UMA ABORDAGEM ANALÍTICA
}

Silvio Aparecido Crepaldi ${ }^{1}$

\begin{abstract}
RESUMO
Nos últimos anos, cresceu notavelmente o interesse mútuo entre o Brasil e a China. Na década de 1990 ambos os países se esforçaram para promover a multi-polarização do poder mundial e fortalecer a cooperação entre países em desenvolvimento. Brasil e China trabalham com vistas à consolidação de uma parceria estratégica, o que tem impulsionado as relações bilaterais; mas há ainda desafios a serem superados. Com esta realidade surge uma lacuna na bibliografia sobre os aspectos relevantes da aproximação Brasil e China. Assim, a carência de bibliografias voltadas ao assunto que incluam o estudo desta aproximação e seus reflexos, motiva à pesquisa visando sanar essas deficiências. Pretende-se analisar as relações comerciais sino-brasileiras de 1984 a 2002 e explorar o significado do conceito de parceria estratégica no relacionamento dos dois países. Antes disso, contudo, são indispensáveis algumas ponderações extraídas da sua análise global, permitindo a melhor reflexão e apontamento de conclusões sobre as relevantes matérias tratadas na referida aproximação Brasil e China. Em conseqüência do cenário exposto, a problemática pode ser sintetizada na seguinte questão: "como Brasil e China deveriam interagir entre si para obter uma inserção mutuamente vantajosa no mundo globalizado?". As informações referentes ao tema aproximação entre Brasil e China foram obtidas mediante pesquisa bibliográfica. $\mathrm{O}$ volume das transações comerciais entre Brasil e China vem evoluindo rapidamente e a China tornou-se recentemente o maior parceiro comercial do Brasil na Ásia. Há ainda enormes potencialidades comerciais a serem exploradas. Ao mesmo tempo, a economia chinesa consegue gerar empregos urbanos em escala astronômica. Somente nos primeiros 9 (nove) meses deste ano, foram criados cerca de 8 milhões de postos de trabalho nas cidades da China.
\end{abstract}

Palavras Chaves: Aproximação Brasil e China, Parcerias, Relações Comerciais.

\section{ABSTRACT}

In the last years, notavelmente grew the mutual interest between Brazil and China. In the decade of 1990 both the countries if had strengthenn to promote the multi-polarization of the world-wide power and to fortify the cooperation between developing countries. Brazil and China work with sights to the consolidation of a strategical partnership, what it has stimulated the bilateral relations; but it has still challenges to be surpassed. With this reality a gap in the bibliography appears on the excellent aspects of the approach Brazil and China. Thus, the lack of bibliographies directed to the subject that include the study of this approach and its consequences, motivates to the research aiming at to cure these deficiencies. The 2002 are intended to analyze the commercial relations 1984 bell-Brazilians and to explore the meaning of the concept of strategical partnership in the relationship of the two countries. Before this, however, some extracted balances of its global analysis are indispensable, allowing to the best reflection and note of conclusions on the excellent substances treated in the related approach Brazil and China. In consequence of the displayed scene, the problematic one can be synthecized in the following question: "as Brazil and China they would have to interact between itself to get a mutuamente advantageous insertion in the globalizado world". The referring information to the subject approach between Brazil and China had been gotten by means of bibliographical research.The volume of the commercial transactions between Brazil and China comes evolving quickly and China recently became the biggest commercial partner of Brazil in Asia. It has still enormous commercial potentialities to be explored. At the same time, the Chinese economy obtains to generate urban jobs in astronomical scale. Only in first the 9 (nine) months of this year, they had been created about 8 million ranks of work in the cities of China.

Keys Words: Commercial approach Brazil and China, Partnerships, Relations.

\footnotetext{
${ }^{1}$ Docente da Faculdade de Administração do IMES / FUMESC - Machado - MG
} 
Revista Eletrônica de Ciência Administrativa (RECADM) - ISSN 1677-7387

Faculdade Cenecista de Campo Largo - Coordenação do Curso de Administração

v. 4, n. 1, maio/2005 - http://revistas.facecla.com.br/index.php/recadm/

\section{SUMÁRIO}

1 Introdução; 2 Brasil-China: uma aproximação benfazeja; 3 As diferenças culturais entre Brasil e China diante dos 30 anos de estabelecimento diplomático; 4 Acordo de livre comércio; 4.1Importância estratégica; 4.2 Brasil começa a transferir tecnologia e a terceirizar; 50 avanço dos chineses; 6 Análise da situação econômica global; 7 Conclusão; 8 Referências Bibliográficas.

\section{INTRODUÇÃO}

Nos últimos anos, cresceu notavelmente o interesse mútuo entre o Brasil e a China. Um dos frutos dessa aproximação é o crescente espaço que a mídia brasileira dá às questões que envolvem os dois países, segundo ABDENUR (1994).

Desde o estabelecimento das relações diplomáticas, em 1974, houve períodos de relativo afastamento; atualmente o relacionamento entre os dois países caracteriza-se por clima de cordialidade e aproximação, tendo-se registrado um grande avanço em várias áreas. Na década de 1990 ambos os países se esforçaram para promover a multi-polarização do poder mundial e fortalecer a cooperação entre países em desenvolvimento. Brasil e China trabalham com vistas à consolidação de uma parceria estratégica, o que tem impulsionado as relações bilaterais; mas há ainda desafios a serem superados. As trocas comerciais estão muito aquém do nível a que se poderia aspirar em vista da dimensão dos dois países e do grau de sofisticação das duas economias. 0 fortalecimento das relações sino-brasileiras poderá servir como mola propulsora do desenvolvimento, como um meio eficiente que ajudará a reforçar os papéis que exercem em seus respectivos continentes, criando assim pólos de liderança regional e reforçando suas posições no cenário internacional. A coincidência de pontos de vista no que diz respeito a temas da conjuntura internacional, especialmente visível quando analisada a sintonia da atuação nos foros multilaterais, deixa clara a importância da aliança estratégica entre os dois países. A entrada da China na OMC Organização Mundial do Comércio e a crescente abertura de sua economia representam novas perspectivas e novas oportunidades de cooperação. É uma potência econômica com um mercado consumidor em expansão, com capacidade de absorver capitais e produtos em grande escala. $\mathrm{O}$ peso e a influência da China no Pacífico Asiático é cada vez mais proeminente. Como dois espaços geo-econômicos e culturais de grande dinamismo no mundo atual, Brasil e China têm muita experiência a trocar e muita sinergia a compartilhar.

Os acordos abrangem áreas como infra-estrutura, segurança de produtos alimentícios, saúde, vigilância de medicamentos, ciência e tecnologia, concessão de vistos e esportes. Comprometem-se com o desenvolvimento estável e de longo prazo da cooperação econômico-comercial bilateral e reiteram a importância da aliança entre os países em desenvolvimento. A parceria sino-brasileira é considerada como parte essencial da relação transregional entre a Ásia e a América Latina.

Entre os temas está a questão dos direitos humanos. Os presidentes, do Brasil e China, manifestaram sua não-conformidade com a universalização à adoção de critérios seletivos - uma 
Revista Eletrônica de Ciência Administrativa (RECADM) - ISSN 1677-7387

Faculdade Cenecista de Campo Largo - Coordenação do Curso de Administração

v. 4, n. 1, maio/2005 - http://revistas.facecla.com.br/index.php/recadm/

referência explícita aos Estados Unidos - que diversas vezes propuseram à Comissão de Direitos Humanos da ONU resoluções condenando a violação dos direitos humanos na China, ao mesmo tempo em que ignoram as violações em países que são seus aliados.

O Brasil reconheceu, como exigido pela China dos países com os quais mantêm relações diplomáticas, que Taiwan e o Tibete são partes inseparáveis do território chinês. Outro ponto é a união de forças para reduzir a pobreza em âmbito mundial e para impulsionar negociações comerciais que reflitam os interesses dos países em desenvolvimento.

O Brasil menciona, mas sem profundidade, a questão dos direitos humanos na China, enquanto os chineses pediram ao Brasil que considerem o país como uma economia de mercado em organismos internacionais.

Os argumentos aqui apresentados sugerem que o fim do regime militar, nos anos 80 , não introduziu maiores alterações na política externa brasileira. Diferentemente de outros países da América Latina, o processo de redemocratização no Brasil teve somente um efeito residual na condução da política internacional. Apesar da mudança política e tímida liberalização econômica, a política externa ainda constitui um dos instrumentos centrais da política nacional de desenvolvimento. $\mathrm{E}$, se as relações com a Ásia forem analisadas sob essa perspectiva, quatro pontos merecem destaque especial:

Com esta realidade surge uma lacuna na bibliografia sobre os aspectos relevantes da aproximação Brasil e China. Assim, a carência de bibliografias voltadas ao assunto que incluam o estudo desta aproximação e seus reflexos, motiva à pesquisa visando sanar essas deficiências.

Pretende-se analisar as relações comerciais sino-brasileiras de 1984 a 2002 e explorar o significado do conceito de parceria estratégica no relacionamento dos dois países. Antes disso, contudo, são indispensáveis algumas ponderações extraídas da sua análise global, permitindo a melhor reflexão e apontamento de conclusões sobre as relevantes matérias tratadas na referida aproximação Brasil e China.

Em conseqüência do cenário exposto, a problemática pode ser sintetizada na seguinte questão: "como Brasil e China deveriam interagir entre si para obter uma inserção mutuamente vantajosa no mundo globalizado?". As informações referentes ao tema aproximação entre Brasil e China foram obtidas mediante pesquisa bibliográfica.

\section{BRASIL-CHINA: UMA APROXIMAÇÃO BENFAZEJA}

A partir de 1974, durante o governo do General Ernesto Geisel, o Brasil começou a delinear um processo de aproximação com os chineses, com o restabelecimento de relações diplomáticas e o reconhecimento, pelo governo brasileiro, da República Popular da China, consoante BARBOSA (1993).

Naquela época, o maoismo encontrava-se em um avançado estado de decadência. A morte de Mao Tsé-Tung, em 1976, marcou o começo de significativas mudanças no Partido Comunista Chinês 
Revista Eletrônica de Ciência Administrativa (RECADM) - ISSN 1677-7387

Faculdade Cenecista de Campo Largo - Coordenação do Curso de Administração

v. 4, n. 1, maio/2005 - http://revistas.facecla.com.br/index.php/recadm/

e, dois anos mais tarde, Deng Xiaoping iniciava o caminho das reformas econômicas, ao mesmo tempo em que propiciava a abertura do país aos investimentos estrangeiros.

Abriu-se, assim, um processo de transformações que, entre 1978 e 1998, promoveu um crescimento médio anual do PIB na ordem de 9,8\%, aumentando o PIB per capita de US\$ 45 para US\$ 770. Este incremento foi acompanhado de significativas transformações sociais e culturais certamente espetaculares. Como resultado dessas significativas ações são muito numerosos os problemas e desafios que enfrenta a China de hoje. Do Ocidente ouvem-se múltiplas críticas - muitas justificadas - às contínuas violações dos direitos humanos. Contudo, por mais que se deva esperar melhoras e mudanças substanciais na sociedade chinesa, visto em perspectiva histórica, os avanços observados no conjunto do país são sumamente notáveis, considerando a prosperidade alcançada pela população mesmo que submetida a uma limitada liberalização do regime político.

Durante os anos do maoismo (1949-1976), o Partido Comunista Chinês controlou totalitariamente a vida dos indivíduos em seus mínimos detalhes, com maior ênfase em um ou outro aspecto, dependendo do momento. Uma das manifestações mais perversas deste fenômeno foi a catalogação da população em grupos em que Ihes rotulavam etiquetas políticas positivas ou negativas, dependendo da origem social e da posição assumida ante a Revolução. O controle que se exercia sobre decisões muitas vezes estritamente pessoais, como a escolha do cônjuge, do posto de trabalho ou o lugar para residir, afetou a todos e a cada um dos homens e mulheres do grande continente chinês. Entre algumas das mais nefastas iniciativas do denominado "Grande Timoneiro" cabe destacar a política do "Grande Salto Adiante", no final dos anos cinqüenta e princípios dos sessenta, que teve como saldo a morte de mais de trinta milhões de pessoas, quando a China sofreu uma das mais devastadoras agruras sociais do Século XX. Suas conseqüências resultaram, inclusive, maiores do que a posterior Grande Revolução Cultural Proletária, a partir de 1966, cujo custo em vidas humanas e destruição patrimonial foi também elevado.

Sob esta ótica, as cotas de liberdade e bem estar social alcançadas na China atual são, indubitavelmente, de grande amplitude. O processo de transição chinês, em contraposição com o ocorrido na antiga União Soviética, não somente permitiu um importante desenvolvimento econômico, mas, também tem sido acompanhado de uma certa estabilidade social, se bem que interrompida com os acontecimentos que culminaram na sangrenta intervenção do Exército Popular, em junho de 1989, como reação às mobilizações estudantis na Praça de Tiananmen. Naturalmente, as estruturas de poder mantiveram uma linha de continuidade com a hegemonia do Partido Comunista Chinês que, entretanto, foi dissipando, gradualmente, o que foram os dois grandes pilares de sua política durante o maoismo: a planificação estatal da economia e o controle social. A ideologia do partido, nestes aspectos, pouco ou nada tem a ver com aquele tempo.

Entretanto, o Partido Comunista Chinês, necessitando de legitimação política e sem renegar completamente o seu passado, em parte para evitar assumir todas as responsabilidades que dele se derivaram, continua promovendo um exacerbado nacionalismo. A história das humilhações sofridas pela China, em mãos dos japoneses e de algumas potências ocidentais, durante o Século XIX e 
Revista Eletrônica de Ciência Administrativa (RECADM) - ISSN 1677-7387

Faculdade Cenecista de Campo Largo - Coordenação do Curso de Administração

v. 4, n. 1, maio/2005 - http://revistas.facecla.com.br/index.php/recadm/

princípios do século XX, é insistentemente recordada nas mais diversas instâncias oficiais. Daí resulta a relevância que tiveram os acontecimentos, como a recuperação de Hong Kong, em 1997, e Macau, dois anos mais tarde, bem como o fato da reunificação de Taiwan seja apresentada como irrenunciável nos discursos das elites chinesas e nos pronunciamentos oficiais do governo.

Após a morte de Deng Xiaoping, em fevereiro de 1997, e a ascensão de Jiang Zemin como secretário-geral, e, mais recentemente, Hu Jintao, os passos dados pela nova direção colegiada do Partido Comunista Chinês têm manifestado o firme propósito de continuar o processo de reformas. A insistência da China para obter a sua readmissão na Organização Mundial do Comércio, visto que pertencia ao antigo GATT, até 1949, nos brinda uma indicação mais próxima da vontade política do gigante asiático. Por sua parte, a União Européia e os Estados Unidos, apostam em plenas relações com a República Popular da China, fundamentalmente com o objetivo de incrementar os intercâmbios comerciais, mas, também, como fator impulsionador de transformações políticas e, em especial, de estabilidade nessa região do planeta. Indubitavelmente, o êxito com que está se desenvolvendo a transição sócio-econômica na China, que satisfaz, momentaneamente, as expectativas de amplos setores da população, torna previsível que uma eventual democratização do sistema político se dilate consideravelmente no tempo.

O Brasil, em contraste com vários países da União Européia e da Ásia, conta em sua aproximação com a China com a vantagem de não ter participado na história de suas humilhações. Entretanto, encontra-se bastante defasado com respeito ao nível de conhecimentos sobre aquele portentoso país, o que de certo modo torna-se fator inibidor ao desenvolvimento de relações diplomáticas, comerciais e culturais mais satisfatórias. No âmbito político e empresarial se reconhece a importância que a Ásia Oriental tem no novo contexto da globalização. Todavia, é necessário definir, claramente, o papel que o Brasil deve desempenhar neste fascinante processo de transição da história chinesa. E é nesta direção que as Universidades brasileiras devem voltar suas atenções, utilizando-se da ajuda de entidades públicas e privadas, como sói ocorrer nas nações mais desenvolvidas, promovendo, dentro da vida acadêmica, atividades docentes e de investigação relacionadas com a China e suas diversas facetas sociais, econômicas, culturais e políticas. Certamente, a aproximação entre os dois portentosos países abrem novas e promissoras perspectivas, independentemente das formas de governo que norteiam as suas ações políticas.

\section{AS DIFERENÇAS CULTURAIS ENTRE BRASIL E CHINA DIANTE DOS 30 ANOS DE}

\section{ESTABELECIMENTO DIPLOMÁTICO}

As comemorações em relação aos 30 anos de estabelecimento diplomático entre Brasil e China, realizadas em agosto de 2004 ganharam extensões mais amplas do que propriamente a celebração da data em si, representou o êxito da parceria estratégica Sul-Sul. No decorrer destas quase três décadas - é valido lembrar que as primeiras iniciativas de diálogo sino-brasileiro ocorreram em 1881, não atingindo resultados relevantes, seguida de outras tentativas de aproximação também pouco significativas - os dois países consolidaram um notável patrimônio 


\section{Revista Eletrônica de Ciência Administrativa (RECADM) - ISSN 1677-7387 \\ Faculdade Cenecista de Campo Largo - Coordenação do Curso de Administração v. 4, n. 1, maio/2005 - http://revistas.facecla.com.br/index.php/recadm/}

conjunto nos campos político-diplomático, econômico-comercial e científico tecnológico, destarte DUQUING (1999). As conquistas não param por aí, a manifestação do atual governo brasileiro em relação a política de prioridade com a China, e por outro lado o interesse chinês em relação ao maior país da América do Sul, proporciona novas e promissoras oportunidades para ambos.

A China há tempos concentra esforços no intuito de inserir-se completamente neste cenário da globalização, processo típico da segunda metade do século XX que conduz a crescente integração das economias e das sociedades dos vários países especialmente no que toca à produção de mercadorias e serviços, aos mercados financeiros, e à difusão de informações.Todavia as distâncias, e não se refere a geográfica, mas a cultural tem sido o grande obstáculo nas prospecções de empreendimentos e nas iniciativas comerciais na China.

A adoção de comportamentos de imensa ponderação e receio frente a um suposto e indispensável código de símbolos chinês, parte supostamente constitutiva do universo das negociações comerciais do país, conduzida por uma significante parcela de interessados no mercado da China, além de errônea afasta ou retarda oportunidades potenciais.

O executivo chinês é similar a qualquer executivo do mundo, busca a obtenção de vantagens, lucros e a expansão dos negócios. Obviamente possui características próprias, típicas da cultura a qual pertence, por exemplo através do que eles chamam de guanxi, ou seja o relacionamento baseado no conceito da ligação pessoal de confiança, é fator bastante considerado nas negociações, e em sua ausência os critérios acerca da qualidade, preço, credibilidade da empresa bem como todas os requisitos geralmente ponderados em qualquer instituição de qualquer parte do mundo será a opção a ser utilizada. A lenda difundida em relação a sensibilidade dos chineses frente ao cumprimento de regras especificas comerciais, que envolvem desde palavras até efetivamente a ratificação do acordo em si geram estratégias muitas vezes desnecessárias.

É valido lembrar que os chineses são muito práticos e bastante minunciosos, diante de um contrato, por exemplo, costumam ser extremamente atentos em relação ao significado das palavras realizando alterações muitas vezes consideradas como sinônimos. São detalhes simples que atingiram grandes proporções no imaginário geral, talvez em virtude dos mistérios que o Oriente em si representa.

Gradualmente as diferenças tendem a ser menos distantes e as relações mais próximas, proporcionando entrosamento e naturalidade, assim geradas a partir das experiências e necessidades descobertas empiricamente. Casos bem sucedidos de iniciativas brasileiras na China e vice-versa são cada vez mais comuns, tanto que a China tornou-se o segundo maior parceiro comercial do Brasil. O grande fascínio em relação ao mercado chinês está diretamente associada aos seus números exorbitantes, acerca da população de 1.3 bilhões de habitantes, assim como os indicativos referentes a evolução da economia e a média de crescimento anual.

A intensificação do comércio com a China faz parte das iniciativas da diplomacia comercial brasileira aliada aos esforços dos exportadores nacionais. Em ação recente, a APEX - Agência de Promoção de Exportações do Brasil, contratou uma empresa de consultoria responsável por mapear 


\section{Revista Eletrônica de Ciência Administrativa (RECADM) - ISSN 1677-7387 \\ Faculdade Cenecista de Campo Largo - Coordenação do Curso de Administração v. 4, n. 1, maio/2005 - http://revistas.facecla.com.br/index.php/recadm/}

15 setores econômicos nos quais os produtos brasileiros podem ser mais competitivos no mercado chinês.

Entre os segmentos que serão pesquisados encontram-se calçados, produtos alimentícios, móveis, equipamentos médico-hospitalares, mármores e granitos, cosméticos, tecnologia bancária e softwares. As avaliações acerca das perspectivas de investimentos são promissoras nas áreas de metalurgia do alumínio e produção de fármacos.

Quanto às oportunidades de negócio via transferência de tecnologia ou formação de joint ventures, destacam-se os setores aeroespacial e de infra-estrutura. O programa brasileiro de desenvolvimento de satélites ganha novo impulso, o programa de cooperação sino-brasileiro prevê o desenvolvimento de mais dois satélites. Essa cooperação técnico-científica também tende a se ampliar, o fluxo de delegações chinesas ao Brasil é intenso, com repercussões positivas em diferentes segmentos industriais, assim como na área de pesquisa. O Brasil e a China oferecem, hoje, o maior potencial de negócios no setor de infra-estrutura. É nesse campo que as empresas brasileiras de engenharia pesada podem conquistar vultosos contratos na China, em virtude dos projetos e obras de sucesso já implementados em território brasileiro que atendem as expectativas dos ambiciosos programas de desenvolvimento chinês nas áreas de energia, saneamento, irrigação, construção de moradias, transportes e outras, conforme FUJITA (2001).

No campo comercial, cresce a cada dia o número de empresas brasileiras que vêm conseguindo abrir o mercado chinês para seus produtos.

As experiências contrárias, ou seja, de empresas chinesas que instalam-se ou estão comercializando seus produtos no Brasil também é bastante significativo e vem crescendo rapidamente. Recentemente um grupo multisetorial bastante consolidado na China, o Lunneng Group investiu US\$ 11 milhões para a instalação de uma fábrica de isqueiros, na região sul do país. $\mathrm{Na}$ região da Zona Franca de Manaus e em São Paulo inúmeras empresas do setor eletro-eletrônico e de tecnologia já operam há pelo menos 1 (um) ano, como é o caso da Chint, uma das maiores empresas do setor na China.

Esse entrosamento sino-brasileiro em relação ao fluxo comercial dos dois países poderá atingir, num período relativamente curto, proporções inimagináveis, reflexo de que a integração não apenas econômica como também a cultural ultrapassou o cenário do possível sendo incorporada no âmbito do exeqüível.

\section{ACORDO DE LIVRE COMÉRCIO}

Um acordo de livre comércio entre Brasil e China aumentaria muito as possibilidades de troca de mercadorias entre os dois países, mas no momento ele é impossível de ser concretizado. Esse tipo de acordo tem de ser negociado pelo Mercosul, e não pelos países membros isoladamente. E o Mercosul não pode entrar em entendimento com a China porque o Paraguai não tem relações diplomáticas com aquele país, consoante LAFER (2001).

O governo paraguaio reconhece Taiwan, que vive relação tensa com a China há mais de meio século, desde que a ilha se declarou independente do continente. Os produtos que inundam Ciudad 


\section{Revista Eletrônica de Ciência Administrativa (RECADM) - ISSN 1677-7387 \\ Faculdade Cenecista de Campo Largo - Coordenação do Curso de Administração v. 4, n. 1, maio/2005 - http://revistas.facecla.com.br/index.php/recadm/}

del Leste vêm de Taiwan, o que deixa claro que não se trata de uma questão trivial para aquele país e, portanto, para o Mercosul. Uma pena, pois as autoridades chinesas indicaram que haveria espaço para negociar um acordo. Por isso, resta ao Brasil fazer comércio com os chineses sem preferências tarifárias ou outro privilégio do tipo. Além disso, a prática mostrou que os chineses jogam duro. A devolução de cargas de soja brasileira porque havia uma quantidade de grãos tratados com fungicida acima do permitido deixou claro que o empresário brasileiro não pode bobear.

Ainda assim, o comércio bilateral vem crescendo. De janeiro a setembro de 2002, as exportações brasileiras para lá chegaram a US\$ 4,533 bilhões, um aumento de $28,7 \%$ sobre o mesmo período de 2003. O comércio também cresceu pelo lado das importações, que chegou a US\$ 2,147 bilhões, um crescimento de 73,8\% comparado a 2003. Tudo somado, a corrente de comércio alcançou US $\$ 6,680$ bilhões.

A China é o terceiro mercado para produtos brasileiros, ficando atrás só dos Estados Unidos e Argentina. As vendas de soja totalizaram US\$1,605 bilhões de janeiro a setembro, seguidas pelo minério de ferro e seus concentrados, que atingiram US\$ 768 milhões. Em seguida, vêm o óleo de soja, laminados planos de ferro e aço e pastas químicas de madeira. O país é também o quarto maior fornecedor de produtos para o Brasil. As maiores importações são de partes e aparelhos transmissores ou receptores, seguidos por coques de hulha, dispositivos de cristais líquidos e tecidos. O mercado chinês tem um enorme peso no comércio do Brasil, mas a recíproca não é verdadeira. Em 2003, a China exportou US $\$ 438,250$ bilhões em produtos, dos quais $21,1 \%$ foram para os Estados Unidos. Em seguida, vêm Hong Kong, Japão, Coréia do Sul, Alemanha. O Brasil respondeu por só $0,5 \%$ das vendas chinesas ao exterior em 2003 e a 0,4\% de janeiro a março de 2004. É, portanto, um parceiro com pouco peso na pauta chinesa.

\subsection{Importância Estratégica}

Segundo os diplomatas brasileiros, há de fato diferentes visões sobre a importância estratégica dos dois países. Para o Brasil, a China é uma mina de ouro, um mercado gigantesco onde se pode vender praticamente tudo, e em grandes quantidades. Já para a China, a aproximação com o Brasil tem um peso muito mais político do que comercial. O país asiático luta para ser reconhecido como uma economia de mercado e um aliado latino-americano seria útil, segundo LAFER (2002). Esse tema foi abordado na visita do presidente chinês, Hu Jintao. Entre os integrantes do governo que lidam com o comércio exterior, há uma curiosidade sobre quanto os chineses estariam dispostos a pagar para conseguir o apoio.

Apesar do espaço reduzido para negociações comerciais, há várias possibilidades que já estão sendo exploradas. O Brasil centra foco na remoção das barreiras sanitárias que hoje impedem a venda de carne fresca àquele país. Os negociadores também pressionam para que a China adote o álcool de cana em sua matriz energética e querem explorar o potencial de venda de frutas cítricas.

Outro nicho que poderá render divisas é o do turismo. Recentemente, a China concedeu ao Brasil status de "destino autorizado". Os chineses não podem viajar para qualquer lugar no mundo, 


\section{Revista Eletrônica de Ciência Administrativa (RECADM) - ISSN 1677-7387 \\ Faculdade Cenecista de Campo Largo - Coordenação do Curso de Administração v. 4, n. 1, maio/2005 - http://revistas.facecla.com.br/index.php/recadm/}

mas podem vir ao País. Um dos protocolos assinados pelo presidente Luiz Inácio Lula da Silva em sua visita àquele país, em maio, trata justamente no início de operação de uma linha regular entre o Brasil e a China, uma associação entre a Varig e a Air China. A linha deveria começar a operar em dezembro, mas o mais provável é que fique para janeiro de 2005. Faltam acertar detalhes com a Alemanha, onde os vôos farão escala.

Os maiores projetos sobre a mesa no momento envolvem a Vale do Rio Doce. Os chineses têm interesse em minério de ferro e aço e são fornecedores do carvão mineral utilizado pelas siderúrgicas. Está em discussão um grande projeto que prevê a implantação de uma siderúrgica no Maranhão e a reforma do porto de Itaqui. De lá, sairão aço e soja em direção à China e chegará o carvão.

Quando esteve na China, em maio de 2004, Lula levou a maior delegação de empresários já reunida pelo governo: 450 (quatrocentas e cinqüenta) pessoas. Em setembro do mesmo ano, houve a Expo Brasil China, em Pequim, reunindo 86 (oitenta e seis) empresas brasileiras. O presidente chinês chegou ao Brasil, em março de 2005, com 150 (cento e cinqüenta) empresários. Foi aberta a Exposição de Produtos e Tecnologia da China, em São Paulo. Cinco seminários explorararam as possibilidades de negócios nas seguintes áreas: turismo, telecomunicações, ferrovia, indústria, minas e energia.

\subsection{Brasil começa a transferir tecnologia e a terceirizar}

No movimento de aproximação comercial entre Brasil e China, as pequenas e médias empresas nacionais estão descobrindo que, apesar do porte, também podem fazer negócios com o mesmo perfil das grandes. A terceirização e transferência de tecnologia estão entre as ações em andamento para ampliar a participação dessas empresas naquele mercado. Algumas empresas estão terceirizando a fabricação na China até para conquistar outros mercados além daquele. Uma empresa do Rio de Janeiro, que produz tapetes (um tipo de calçado), está preste a fechar sua primeira parceria com uma indústria chinesa para fabricar naquele país. O custo é mais baixo na China.

\section{O AVANÇO DOS CHINESES}

No mundo das relações diplomáticas, os presidentes do Brasil e da República Popular da China já podem ser considerados bons amigos. Depois da visita de Luiz Inácio Lula da Silva à China em maio de 2004, houve a Expo Brasil China, em Pequim, reunindo 86 (oitenta e seis) empresas brasileiras; foi a vez de Hu Jintao vir ao Brasil, acompanhado de uma comitiva que passou quase uma semana entre São Paulo, Rio e Brasília em novembro de 2004. Nesta ocasião foi aberta a Exposição de Produtos e Tecnologia da China, em São Paulo. Cinco seminários exploraram as possibilidades de negócios nas seguintes áreas: turismo, telecomunicações, ferrovia, indústria, minas e energia. Agora, o presidente chinês também acaba de obter uma prova dessa amizade na esfera comercial. Atendendo a uma antiga reivindicação, o Brasil passou a considerar a China uma "economia de mercado", o que deve facilitar ainda mais a entrada de produtos chineses no Brasil. 


\section{Revista Eletrônica de Ciência Administrativa (RECADM) - ISSN 1677-7387 \\ Faculdade Cenecista de Campo Largo - Coordenação do Curso de Administração v. 4, n. 1, maio/2005 - http://revistas.facecla.com.br/index.php/recadm/}

Não que esteja muito difícil para a China vender mais por aqui. Em apenas um ano, as importações brasileiras de produtos chineses cresceram 74\% e chegaram a 2,6 bilhões de dólares. Uma das estrelas é o setor de telecomunicações. Em 12 meses, a entrada de equipamentos chineses dessa indústria no Brasil cresceu $110 \%$, para um total superior a 420 milhões de dólares no mundo todo, o avanço chinês foi de 55\%. Esses números mostram que a estratégia adotada por $\mathrm{Hu}$, ao internacionalizar suas empresas de tecnologia, dá cada vez mais frutos.

\section{ANÁLISE DA SITUAÇÃO ECONÔMICA GLOBAL}

Obviamente, muitos países do mundo vêm se beneficiando da bonança econômica propiciada pela China. Um deles é o Brasil, que, de sua parte, também contribui significativamente para alimentar o crescimento econômico chinês, graças às suas exportações de commodities estratégicas e à disponibilização de tecnologia avançada em algumas áreas, como na aviação comercial, por exemplo. Mas nem sempre foi assim. Houve época em que as duas grandes nações estavam separadas pelo maniqueísmo ideológico da Guerra-Fria e pelas grandes distâncias geográficas. Findo aquele conflito político-ideológico, constatou-se que as grandes distâncias geográficas não mais se constituíam em obstáculos intransponíveis à aproximação entre as duas nações. Assim, Brasil e China descobriram-se por inteiro. Nos últimos anos, construíram parceria estratégica verdadeiramente modelar em todas as áreas, apesar de estarem em pontos opostos do planeta. Trata-se de um dos mais importantes promotores das reformas econômicas chinesas na década de 90, de uma parceria estratégica entre o maior país em desenvolvimento do hemisfério ocidental e o maior país em desenvolvimento do hemisfério oriental, a qual vem contribuindo para redesenhar o espaço geopolítico mundial.

No campo econômico-comercial, os resultados da cooperação bilateral só podem ser definidos como fantásticos. O dinamismo econômico da China, aliado à qualidade e aos preços competitivos dos produtos Made In Brazil, fêz com que as exportações brasileiras para aquele país sextuplicassem, no período de 1999 a 2003. Ressalte-se que, com o governo Lula, que tomou a decisão estratégica de diversificar as parcerias comerciais e diplomáticas do Brasil, houve notável aceleração desse incremento do comércio bilateral com a China. Em 2003, as exportações para a China cresceram $80 \%$, tendo atingido a impressionante marca de US\$ 4,5 bilhões. Neste ano, aquele país tornou-se o segundo maior importador de produtos brasileiros, suplantando a Argentina e sendo superada somente pelos EUA. Em contrapartida, o Brasil tornou-se um dos principais fornecedores de soja, minério de ferro, aviões comerciais e motores automotivos, além de outros produtos, da economia chinesa. Em relação aos investimentos, as joint ventures entre a Companhia Vale do Rio Doce e a Baogang Steel e a Embraer e a AVIC, além de outras de grande relevância, vêm propiciando base sólida para grande expansão dos investimentos diretos, no âmbito da cooperação bilateral.

No campo científico-tecnológico, o programa sino-brasileiro CBRES (Satélites Sino-Brasileiros de Recursos Terrestres) já lançou dois satélites de monitoramento de recursos terrestres, com grande 


\section{Revista Eletrônica de Ciência Administrativa (RECADM) - ISSN 1677-7387 \\ Faculdade Cenecista de Campo Largo - Coordenação do Curso de Administração v. 4, n. 1, maio/2005 - http://revistas.facecla.com.br/index.php/recadm/}

êxito. Esse programa é considerado modelar no âmbito da cooperação científica internacional, pois dificilmente nações abrem as suas tecnologias de ponta em projetos de assistência mútua, como o fazem Brasil e China. Ademais, a mencionada união entre a Embraer, um dos principais fabricantes de aviões do mundo, e a AVIC vem ensejando vários projetos de cooperação científica na área do transporte aeroviário, segundo SANTANA e COELHO (1999).

Embora tais realizações econômicas, comerciais e científicas sejam de enorme significado para ambos os países, parece que é no campo político-diplomático que a dimensão estratégica da parceria sino-brasileira torna-se evidente. De fato, tal parceria tende inexoravelmente a modificar o espaço geopolítico mundial e a geografia comercial do planeta, ao criar um novo eixo de cooperação entre países em desenvolvimento, fora da dependência tradicional relativa aos países desenvolvidos. A criação do G-20, por exemplo, de iniciativa brasileira, mas impensável sem a China e outros países, resultou em poderoso novo ator no cenário mundial, o qual tornou mais equilibrada a correlação de forças em nível global. Nas negociações comerciais que se desenvolvem na OMC, o G-20 conseguiu contrapor-se aos interesses comerciais hegemônicos e gerar espaço para que os países em desenvolvimento reivindicassem os seus legítimos anseios antiprotecionistas.

Em relação ao sistema de segurança coletiva, tão ameaçado, a união de Brasil e China em torno do necessário fortalecimento e da democratização da ONU e do seu Conselho de Segurança tende a mitigar os efeitos deletérios de políticas unilateralistas na ordem internacional. Destaque-se também a firme posição de nossos países em prol da condução da luta contra o terrorismo nos marcos do direito internacional público. Portanto, a parceria estratégica sino-brasileira, além de produzir conseqüências relevantes no contexto bilateral, está também contribuindo para a conformação de ordem mundial mais justa, equilibrada e estável.

Em um mundo caracterizado por relações internacionais marcadas pela verticalidade e pela assimetria, Brasil e China consagraram padrão de cooperação horizontal e simétrico entre dois países em desenvolvimento, que serve de parâmetro para o relacionamento Sul-Sul. Com efeito, nossas nações pautam a sua parceria pelos "cinco princípios da coexistência pacífica" apregoados por Chu En-Lai: respeito mútuo à soberania e integridade territorial, não-agressão, não-intervenção nos assuntos internos, igualdade e benefícios recíprocos e tolerância entre diferentes sistemas ideológicos.

Menciona-se que, em virtude do primeiro princípio, o governo brasileiro, assim como a maior parte dos governos do mundo e a Organização das Nações Unidas, reconhece a plena soberania do governo da República Popular da China sobre a província de Taiwan.

A recente viagem à China do Presidente Lula e a presente visita do Presidente Hu Jintao ao Brasil deverão adensar ainda mais essa exemplar parceria. Só no campo da iniciativa privada, estão sendo implementados 14 novos convênios entre empresas chinesas e brasileiras. No tocante aos investimentos diretos, foram divulgados cerca de US\$ 5 bilhões que a China deverá injetar na economia brasileira nos próximos anos. Projetos tão diversificados como a modernização dos portos de Itaquí, São Sebastião e Santos, a construção de ferrovias e rodovias no Maranhão e em São 


\section{Revista Eletrônica de Ciência Administrativa (RECADM) - ISSN 1677-7387 \\ Faculdade Cenecista de Campo Largo - Coordenação do Curso de Administração v. 4, n. 1, maio/2005 - http://revistas.facecla.com.br/index.php/recadm/}

Paulo, gasodutos em diversos pontos do país, bem como siderúrgicas e usinas petroquímicas deverão contar com o apoio substancial dos nossos amigos chineses.

$\mathrm{Na}$ área científico-tecnológica, serão iniciados programas importantes em biotecnologia, pesquisas de genoma, telecomunicações, robótica, além de outros temas relevantes.

No campo cultural, há muito espaço a ser explorado. A duas nações compartilham traços sócioculturais importantes, graças à colonização portuguesa, que formou vínculos históricos entre Brasil e China, no início da colonização brasileira. Para ele, o Brasil era uma espécie de "China Tropical". Esses vínculos histórico-culturais talvez expliquem, em parte, o imenso sucesso da novela "Escrava Isaura" na China. Agora, vamos aprofundar tais vínculos, dinamizando o intercâmbio cultural em todas as áreas: literatura, audiovisual, artes plásticas, teatro, dança e música. Especificamente no campo esportivo, o Brasil espera enviar à Beijing, em 2008, uma grande delegação olímpica, de modo a prestigiar a organização chinesa do evento, a qual será, sem dúvida, exemplar. Felizmente, tanto o governo brasileiro quanto o chinês reconhecem a importância da cultura para criar pontes duradouras entre os nossos povos e aprofundar a parceria estratégica Brasil/China.

O governo brasileiro, consciente da importância da política externa para a promoção de projeto nacional de desenvolvimento, está fortemente empenhado na consolidação dessa e de outras parcerias estratégicas, com o intuito de induzir o crescimento econômico e a geração de empregos, assim como de reduzir a vulnerabilidade externa do país mediante a geração de vultosos superávits comerciais. A China, que tem no Brasil um aliado para manter as suas taxas de crescimento econômico e ampliar o seu peso econômico-comercial e político-diplomático no cenário mundial, revelou-se parceiro interessado, generoso e que faz aposta de longo prazo no futuro do Brasil, aproveitando-se da omissão e da intransigência protecionista de algumas potências econômicas.

Entretanto, a China não vem apenas ajudando outros países a prosperarem e contribuindo para a conformação de ordem mundial mais simétrica. Acreditamos que o notável despertar da China está dando a muitas nações duas lições valiosas.

A primeira delas refere-se ao equilíbrio que aquele país encontrou entre os mecanismos da economia de mercado, indispensáveis para o crescimento econômico acelerado, e a presença marcante do Estado planejador e regulador, necessária para orientar esse crescimento na direção correta e distribuir suas benesses de forma justa.

A idéia de "um só país e dois sistemas", do gênio pragmático Deng Xiaoping, revelou-se acertada e premonitória e conduziu a China à prosperidade econômica sem sobressaltos, ao contrário do ocorrido em outras nações socialistas que, mal-aconselhadas por economistas sem crédito e pressionadas por instituições de crédito, fizeram transição atabalhoada para um capitalismo sem regulação. Nesses países, bem como em outros, a "mão invisível" produziu estragos bem visíveis.

A segunda lição, mais profunda e relevante, tem como base o humanismo de cunho universalista presente na cultura chinesa. Confúcio, em seus Livros Clássicos, afirma que: Ao largo dos quatro mares todos os homens são irmãos e que Desejando sermos prósperos devemos ajudar 


\section{Revista Eletrônica de Ciência Administrativa (RECADM) - ISSN 1677-7387 \\ Faculdade Cenecista de Campo Largo - Coordenação do Curso de Administração v. 4, n. 1, maio/2005 - http://revistas.facecla.com.br/index.php/recadm/}

outros a atingir a prosperidade. Vinte e quatro séculos mais tarde, Deng Xiaoping disse: Como país socialista, a China sempre pertencerá ao Terceiro Mundo e nunca deverá perseguir hegemonia.

Citou-se, de forma proposital, dois autores muito separados temporal e ideologicamente para demonstrar que a idéia de uma necessária solidariedade entre homens e países sempre foi forte no imaginário chinês. A China, pelo seu peso demográfico, econômico e político-diplomático, está destinada a liderar, assim como o Brasil também o está, pelos mesmos motivos. Contudo, a China não tem pretensões de transformar essa saudável liderança numa deturpada imposição de hegemonia. É esta a segunda lição, a da construção de liderança sem imposição de hegemonia, respeitosa do multilateralismo, que devemos destacar nesse despontar da China no cenário internacional. Destaque-se que o Brasil pauta a sua liderança regional pelo mesmo princípio, conforme TEIXEIRA LEITE (1999).

\section{CONCLUSÃO}

O volume das transações comerciais entre Brasil e China vem evoluindo rapidamente e a China tornou-se recentemente o maior parceiro comercial do Brasil na Ásia. Há ainda enormes potencialidades comerciais a serem exploradas.

Os governos de ambos os países têm em alta conta o relacionamento político já existente entre eles. Apesar das oportunidades crescentes representadas pela abertura externa empreendida por ambos os países ao longo da última década, o aproveitamento em termos comerciais é pouco expressivo. O conhecimento mútuo além dos estereótipos é extremamente restrito, mesmo por parte das elites políticas, empresariais ou acadêmicas. O interesse crescente demonstrado no Brasil pelas relações e pelos projetos de cooperação com a China ainda não rendeu os efeitos esperados, mas há um grande potencial para a cooperação técnico-científica entre os dois países e a perspectiva é de se ampliar e expandir essa cooperação.

Nos últimos três anos, a China foi responsável por um terço do crescimento econômico global, duas vezes mais do que a economia norte-americana. Também no mesmo período (2000-2003), a produção industrial chinesa aumentou impressionantes 50\% (cinqüenta por cento). Com uma população de 1,3 bilhão, a China tem 41 (quarenta e uma) cidades com mais de um milhão de habitantes. Contudo, mantém 900 milhões de habitantes em sua zona rural, graças a uma política agrícola e de abastecimento que privilegia o pequeno produtor e evita migrações desordenadas para as cidades. Ao mesmo tempo, a economia chinesa consegue gerar empregos urbanos em escala astronômica. Somente nos primeiros 9 (nove) meses deste ano, foram criados cerca de 8 milhões de postos de trabalho nas cidades da China.

\section{REFERÊNCIAS BIBLIOGRÁFICAS}

ABDENUR, Roberto. O Brasil e a nova realidade asiática: uma estratégia de aproximação. In: Política Externa, 2 (3): 43-69, 1994.

BARBOSA, Gibson. Depoimento em Reflexões sobre a Política Externa Brasileira. Brasília: Funag, 1993. 
Revista Eletrônica de Ciência Administrativa (RECADM) - ISSN 1677-7387

Faculdade Cenecista de Campo Largo - Coordenação do Curso de Administração

v. 4, n. 1, maio/2005 - http://revistas.facecla.com.br/index.php/recadm/

DUQUING, Chen. Os 25 anos das relações sino-brasileiras. Rio de Janeiro: Tempo Brasileiro. Rio de Janeiro, in: Tempo Brasileiro, 137: 9-29, 1999.

FUJITA, Edmundo. Fórum de Cooperação da América Latina-Ásia do Leste. Primeira Reunião de Chanceleres (Santiago - Março de 2001). São Paulo, in: Carta Internacional, IX (98): 3, 2001.

LAFER, Celso. Lecture at the Rio Branco Institute. Brasília, April 12 $2^{\text {th }}, 2001$.

. Brasil e China em Novos Tempos. in: Gazeta Mercantil. São Paulo, 14/08/2002.

SANTANA, Carlos Eduardo \& COELHO, José Raimundo Braga. O Projeto CBERS de Satélites de Observação da Terra. In: Parcerias Estratégicas, 7: 189-196, Setembro/1999.

TEIXEIRA LEITE, José Roberto. A China no Brasil. Campinas: Editora Unicamp, 1999. 